\title{
References
}

Pagnamenta A, Vanderpool RR, Brimioulle S, et al. Proximal pulmonary arterial obstruction decreases the time constant of the pulmonary circulation and increases right ventricular afterload. J Appl Physiol 2013; 114: 1586-1592. Saouti N, Westerhof N, Helderman F, et al. Right ventricular oscillatory power is a constant fraction of total power irrespective of pulmonary artery pressure. Am J Respir Crit Care Med 2010; 182: 1315-1320.

Tedford RJ, Hassoun PM, Mathai SC, et al. Pulmonary capillary wedge pressure augments right ventricular pulsatile loading. Circulation 2012; 125: 289-297.

4 Lankhaar JW, Westerhof N, Faes TJ, et al. Pulmonary vascular resistance and compliance stay inversely related during treatment of pulmonary hypertension. Eur Heart J 2008; 29: 1688-1695.

5 MacKenzie Ross RV, Toshner MR, Soon E, et al. Decreased time constant of the pulmonary circulation in chronic thromboembolic pulmonary hypertension. Am J Physiol Heart Circ Physiol 2013; 305: H259-H264.

6 Delcroix M, Vonk Noordegraaf A, Fadel E, et al. Vascular and right ventricular remodelling in chronic thromboembolic pulmonary hypertension. Eur Respir J 2013; 41: 224-232.

\section{Sleep quality as a confounding factor of maternal weight and preschool wheezing}

To the Editor:

We read with great interest the recently published article by LEERMAKERS et al. [1] that takes an outstanding view of the relationship of maternal weight with the risk of preschool wheezing. We would like to highlight the importance of this study, as it shows a bidirectional interaction between pregnancy and childhood health. Moreover, we would like to congratulate the authors on the accomplishment of this research and suggest additional considerations for further investigations.

Currently, asthma is the most common chronic disease in children in the USA. It is noteworthy that the incidence of asthma in childhood has progressively increased, being observed $8.7 \%$ of cases in 2001 and $9.6 \%$ in 2009 [2]. For instance, 17\% of children in the USA have a diagnosis of obesity and there is a higher prevalence of asthma in obese children [3]. However, the biological pathway responsible for the association of obesity with asthma is still unclear. There are several hypotheses, as discussed in the article by LEERMAKERS et al. [1].

We would like to discuss another important aspect on this question that refers to the impact of sleep during pregnancy on the health of both the mother and newborn. Pregnancy causes sleep changes between the first months and after the baby is born. About of $75 \%$ of mothers develop some sleep disorder in pregnancy [4], such as poor sleep quality and decreased sleep duration. In addition, pregnant mothers have an increased risk of obstructive sleep apnoea (OSA) [5]. In addition, these sleep disorders are correlated with glucose intolerance, gestational diabetes mellitus, gestational hypertension and preeclampsia [5]. It has been highlighted that diabetes in pregnancy is associated with high birth weight. Furthermore, both poor maternal sleep and OSA can lead to increased proinflammatory cytokine levels [6]. Thus, this factor could be related to increase of proinflammatory cytokine levels in mothers, which might affect the immune system of the fetus, and the risk of infectious and atopic diseases post-natally.

Breastfeeding is important for neonates, as breast milk is the primary component of the infant's diet and meets the essential nutritional requirements of the rapidly growing child. We would like to emphasise which factors may affect breastfeeding and, consequently, neonatal health. There are various bioactive factors in human colostrum and milk, such as immune cells, immunoglobulins, fatty acids, glycoproteins and antimicrobial peptides [7], that lead to inactivation of pathogens. Furthermore, there is melatonin in human milk, a hormone related to Circadian rhythms, particularly with sleep [8]. In addition, melatonin is involved in physiological and oxidative processes, including functional regulation.

The mother's behaviour could be reflected in breastfeeding and it can lead to health consequences for the baby. A study found that mothers who drank alcohol had less active sleep in their children [9]. It is well known that sleep in childhood is important for future health, as children affected by sleep disorders are more susceptible to consequences of sleep problems. There is a relationship between sleep duration during childhood, endocrine disorders and increased body mass index [10]. Sleep disorders and obesity in childhood may lead to increased proinflammatory cytokines, and this may affect the immune system and the risk of infectious and atopic diseases. For this reasons, we suggest the evaluation sleep in pregnant females. 
Considering the consequences of impaired maternal health and its implications for the child, we would like to emphasise the importance of the study by LEERMAKERs et al. [1], which evaluated maternal weight and preschool wheezing, and provides results relevant to society. Currently, weight gain is a worldwide health problem and is of great importance in pregnant females, as the health impacts can be severe, both for the mother and the neonate. We would like to ask the authors and other research groups to include sleep evaluation as a possible confounding factor, as there appears to be relationship between maternal health, obesity, sleep disorders and asthma.

@ERSpublications

Sleep should be evaluated during pregnancy as a confounder of maternal health, obesity and asthma http://ow.ly/tsWuA

Karen Tieme Nozoe, Daniel Ninello Polesel, André Campiolo Boin, Gustavo Antônio Moreira, Sergio Tufik and Monica Levy Andersen

Dept of Psychobiology, Universidade Federal de São Paulo, São Paulo, Brazil.

Correspondence: M.L. Andersen, Rua Napoleão de Barros 925, 04024-002 São Paulo/SP, Brazil. E-mail: ml.andersen12@gmail.com

Received: Nov 192013 | Accepted: Nov 212013

Support statement: The authors wish to acknowledge the Associação Fundo de Incentivo à Pesquisa, the Conselho Nacional de Desenvolvimento Científico e Tecnológico (CNPq) of Brazil and São Paulo Research Foundation (grant \#2012/08587-8 to K.T. Nozoe) for financial support. S. Tufik and M.L. Andersen are recipients of fellowships from CNPq.

Conflict of interest: None declared.

\section{References}

1 Leermakers ET, Sonnenschein-van der Voort AM, Gaillard R, et al. Maternal weight, gestational weight gain and preschool wheezing: the Generation R Study. Eur Respir J 2013; 42: 1234-1243.

2 Zahran H, Bailey C, Garbe P. Vital signs: asthma prevalence, disease characteristics, and self-management education - United States, 2001-2009. Morb Mortal Wkly Rep 2011; 60: 547-552.

3 Ahmad N, Biswas S, Bae S, et al. Association between obesity and asthma in US children and adolescents. J Asthma 2009; 46: 642-646.

4 Okun ML, Roberts JM, Marsland AL, et al. How disturbed sleep may be a risk factor for adverse pregnancy outcomes. Obstet Gynecol Surv 2009; 64: 273-280.

5 Reutrakul S, Zaidi N, Wroblewski K, et al. Interactions between pregnancy, obstructive sleep apnea, and gestational diabetes mellitus. J Clin Endocrinol Metab 2013; 98: 4195-4202.

6 Izci-Balserak B, Pien GW. Sleep-disordered breathing and pregnancy: potential mechanisms and evidence for maternal and fetal morbidity. Curr Opin Pulm Med 2010; 16: 574-582.

Newburg DS. Innate immunity and human milk. Journal of Nutrition 2005; 135: 1308-1312.

8 Cohen Engler A, Hadash A, Shehadeh N, et al. Breastfeeding may improve nocturnal sleep and reduce infantile colic: potential role of breast milk melatonin. Eur J Pediatr 2012; 171: 729-732.

9 Mennella JA, Garcia-Gomez PL. Sleep disturbances after acute exposure to alcohol in mothers' milk. Alcohol 2001; 25: $153-158$.

10 Gozal D, Kheirandish-Gozal L. Childhood obesity and sleep: relatives, partners, or both? A critical perspective on the evidence. Ann NY Acad Sci 2012; 1264: 135-141.

Eur Respir J 2014; 43: 1542-1543 | DOI: 10.1183/09031936.00202113 | Copyright @ERS 2014

\section{From the authors:}

We kindly thank K.T. Nozoe and co-workers for their correspondence regarding our recently published article [1]. They suggested that the observed association of maternal body mass index (BMI) with childhood wheezing might be confounded by maternal sleeping problems during pregnancy. We appreciate this interesting suggestion.

As K.T. Nozoe and co-workers mentioned, asthma is a very common chronic disease amongst children. Given its high prevalence and considerable impact on morbidity and healthcare costs, research focused on early risk factors for asthma is important. Identification of causal risk factors and their mechanisms in pregnancy or early childhood, may lead to the development of new preventive strategies focused on the early phase of life. K.T. Nozoe and co-workers suggested that maternal sleep quality during pregnancy could be an important risk factor for childhood asthma, and that maternal sleep problems might be involved in the pathways underlying the association between maternal obesity and the risk of wheezing in offspring. Because of this possible intermediate effect of sleep in the association between maternal BMI and the risk of wheezing in offspring, sleep problems should not be treated as an extraneous confounding factor $[2,3]$. 